\section{Responsibilities not ducked}

SIR-Your leading article about British research (Nature 343, 293; 1990) alleges that "departments have consistently ducked their responsibilities, notably in agriculture" for implementing the recommendation of the Rothschild report of 1971 "that government departments should stand proxy for the ultimate taxpayer beneficiaries of strategic research".

I am afraid your leader writer has not done his homework. Rothschild said that applied research and development R\&D with the objective of practical application - should be done on a customer/ contractor basis. For agriculture, the report found that a major part of the research funded by the Agricultural Research Council (ARC) was applied, that this work had no customer to commission and approve it, and that this was unsatisfactory.

It was therefore recommended that, while the Department of Education and Science should continue to fund basic and allied strategic research done by the ARC, the Ministry of Agriculture, Fisheries and Food (MAFF) should take over the role of customer for applied research.

The ministry, which already had considerable scientific expertise, therefore set up a Chief Scientists Group and took on the customer role for $\mathrm{R} \& \mathrm{D}$, commissioning research specifically to meet particular needs and objectives.

Subsequent events have modified the

\section{Influenza causing sunspots?}

SIR-Hoyle and Wickramasinghe ${ }^{1}$ describe an association between sunspot maxima and pandemics of influenza, claiming that the relationship may be causal and that it holds over 17 cycles. In a causal relationship, it is conventional that the cause precedes the effect it produces, but in four of Hoyle and Wickramasinghe's cycles, this convention is flouted; the maxima of 1778, 1804, 1860 and 1893 follow the pandemics they are supposed to have caused.

We are not in a position to comment on the quality or accuracy of sunspot data collected in the eighteenth and nineteenth centuries, but doubt must arise about the data concerning the epidemiology of influenza. The difference between an epidemic and a pandemic is a matter of degree, and not all the dates listed by Hoyle and Wickramasinghe can be said to be those of pandemics.

Vaughan $^{2}$ has analysed influenza pandemics and epidemics between 1173 and 1921. Hoyle and Wickramasinghe show a pandemic in 1761-62, but Vaughan shows that this was a period of complica- detail of the arrangements. For example, MAFF's focus is now very much on work that is primarily of benefit to the community at large - food safety, protection of the environment, animal welfare - as well as the strategic underpinning industry needs.

But we remain firmly committed to the customer/contractor principle and fund a substantial and varied programme of R\&D. For MAFF alone this amounts to about $£ 120$ million a year. With the other agriculture departments and the Department of Education and Science the sum totals well over $£ 200$ million.

It is in the nature of our work that science and policy are closely linked. We are now working on ways of strengthening further our 'intelligent customer' capacity, sharpening the distinctive roles of customer and contractor in line with moves across government generally and bringing commercial views to bear more closely on the strategic research we commission.

You and your readers might like to watch out for announcements from us on these issues. I can assure you that ducking responsibilities is the last thing we have in mind.

THE BARONESS TRUMPINGTON (Minister of State)

\section{Ministry of Agriculture}

Fisheries and Food,

Whitehall Place, London SW1A $2 \mathrm{HH}$, UK

ted epidemics with poorly defined geographical distribution extending from 1757 to 1767 . If Vaughan is accepted, then it is difficult to ascribe this series of epidemics to a solar event four years after its beginning.

By contrast, in 1815 influenza spread from New York to Brazil in five months, but this is not cited as a pandemic and, as in the four instances listed above, is followed by the sunspot maximum of 1816 (which Hoyle and Wickramasinghe consider to be too low to be of significance).

The name influenza probably derives from the Italian and carries telluric associations with regard to aetiology and spread. The imprecision of the epidemiological data on influenza make it difficult, at present, to establish a temporal association with solar activity and impossible to establish a causal association.

Department of Medicine,

Beaumont Hospital, Dublin 9, Ireland

Department of Dermatology,

GILLIAN MURPHY

St Thomas's Hospital, London SE1, UK

1. Hoyle, F. \& Wickramasinghe, N. Nature 343,304 (1990)

2. Vaughan, W.T. Am. J.Hyg. Monograph Ser, No. 1, (Baltimore, 1921)

\section{PhD students}

SIR-As a PhD student, it was with grateful relief in September last year that I found that the value of SERC (Science and Engineering Research Council) studentships had been raised by $£ 600$ (outside London) to $£ 3,725$. For me, this meant that I might be able to end my studentship next October without the incumbrance of a weighty overdraft. My bank manager says that this achievement, after six years as a full-time student through both BSc and $\mathrm{PhD}$ degrees, is the exception and not the rule.

There are at present several different types of studentships available, with MRC, SERC and NERC studentships at the lower end, through CASE awards to Wellcome Trust studentships at the top end. Until recently, the difference between them all has been at best $£ 1,000$ a year. I have now learned, however, that Wellcome has increased the level of studentships to the amount received by a research assistant after tax, some $£ 7,300$. Although I feel happy for those lucky few (I share a flat with one), I was left feeling disturbed by the whole affair. The Wellcome Trust makes the point that it hopes this action will prompt the government to raise publicly funded $\mathrm{PhD}$ studentships in the same way.

I doubt, however, that in the current political climate any such move will be made, and Wellcome's action in increasing the value of studentships is likely only further to exacerbate the tension among students on different pay scales who essentially have the same kind of motivation, responsibilities and expectations. The rise for studentships paid last year represents not a real rise in income but a readjustment of the level of the grant which has fallen by some 20 per cent since 1979.

What is perhaps most disturbing is the way in which the student loans system will affect the number of people contemplating starting a $\mathrm{PhD}$ in years to come. Until now, almost all studentships have been filled, indicating to the government that there is still a market demand. Ask any group of final-year biological science students whether they would like to attempt a higher degree and a large proportion will say yes. Ask them if they can afford to take such a course for a further three years, and the answer will be very different. How many will say yes to both questions in a few years' time when the financial effect of the loans scheme has bitten even more deeply? The whole system of $\mathrm{PhD}$ grants requires radical change before it is too late.

D.I. ROPER

Department of Biochemistry,

University of Leicester,

University Road,

Leicester LE1 7RH, UK 